Pathologe 2013 $34: 8$

DOI 10.1007/s00292-012-1701-x

Online publiziert: 9 . Januar 2013

(c) Springer-Verlag Berlin Heidelberg 2013
C. Heydt ${ }^{1,2} \cdot$ R. Büttner ${ }^{1,2}$

${ }^{1}$ Institut für Pathologie, Universität zu Köln

${ }^{2}$ Centrum für Integrierte Onkologie ClO Köln-Bonn, Köln

\title{
Aktuelle Herausforderungen der Pathologie - praktikable Lösungen häufiger Probleme
}

\section{Einführung zum 49. Symposion der deutschen Abteilung der International Academy of Pathology (IAP), 22.-24. Februar 2013 in Bonn}

Das diesjährige Schwerpunktthema des IAP (International Academy of Pathology)-Haupttutorials spannt bewusst einen breiten Bogen von der molekularen Tumorgenetik bis zur klinischen Pathologie. Aktuelle medizinrechtliche und -ethische Aspekte werden in den Blick genommen, da die Bedeutung der Gewebeanalytik durch zunehmenden Einsatz klinisch relevanter Biomarker wächst. Dies gilt nicht nur für Lungen- und Mammakarzinome, Paradigmen der Onkologie solider Tumoren, bei denen Marker wie EGFR („,epidermal growth factor receptor"), ALK (,anaplastic lymphoma kinase") und HER („,human epidermal growth factor receptor") 2 [1-3] entscheidend für den Einsatz bereits zugelassener Therapien sind, sondern auch für viele neue Therapien, die von einer profunden Biomarkeranalytik abhängig und bereits in klinischer Prüfung sind. So gilt mehr denn je der Satz „Tissue is the issue. " und Fragen entstehen, wie etwa "Wem gehört das Gewebe und in welcher Form kann es anderen Laboren überlassen werden?". Die Grenzen zwischen Forschung und individueller patientenbezogener Biomarkeranalytik verschwimmen zusehends.

Gleichzeitig nimmt die Bedeutung neuer Sequenzierverfahren auch in der Pathologie $\mathrm{zu}$, sodass diesem Thema ein eigener Beitrag gewidmet wurde. Im Sommer 2013 wird die IAP diese Thematik in der internationalen Juniorakademie nochmals intensiv aufgreifen.
Auch in vielen anderen Bereichen der histopathologischen Diagnostik haben molekular basierte Diagnostik und Tumorklassifikation Einzug in die tägliche Praxis gehalten, wie unter anderem in den Beiträgen zur Gynäkopathologie und Lymphknotenpathologie deutlich wird. Den rasantesten Fortschritt hat es im letzten Jahr mit den vielen Beiträgen zur molekularen Pathologie von Myelodysplasien und myeloproliferativen Erkrankungen gegeben, die eine Risikostratifizierung erlauben und ebenfalls in diesem Heft dargestellt werden.

Dabei sollten wir als Pathologen streng darauf achten, die Biomarkeranalytik nach qualitätsgesicherten Standards durchzuführen und den Begriff sehr eng zu fassen. Wirklich klinisch relevante Marker zur Stratifizierung von Therapien sind solche, die in der Pathogenese einer Erkrankung eine kausale Rolle spielen, die sich in präklinischen Modellen als Therapieziele eignen und deren Bedeutung in prospektiven klinischen Studien validiert werden konnte [4]. In diesem Verständnis unterscheidet sich die Pathologie fundamental von der laxen Verwendung des Begriffs für korrelative Marker, die z. B. durch serologische Tests bestimmt werden, oder für nicht validierte mRNA-Expressionsanalysen.

Die vielfältigen Themen dieses Hefts und unseres 49. Symposions illustrieren die zunehmende klinische Bedeutung der Pathologie auch in diesem Bereich.

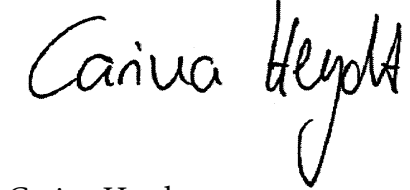

Carina Heydt

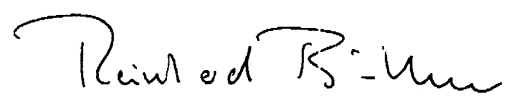

Reinhard Büttner

\section{Korrespondenzadresse}

Prof. Dr. R. Büttner

Centrum für Integrierte Onkologie $\mathrm{ClO}$

Köln-Bonn

Kerpener Straße 62, 50924 Köln

reinhard.buettner@uk-koeln.de

\section{Literatur}

1. Fukuoka M, Wu YL, Thongprasert S et al. (2011) Biomarker analyses and final overall survival results from a phase III, randomized, open-label, first-line study of gefitinib versus carboplatin/paclitaxel in clinically selected patients with advanced non-small-cell lung cancer in Asia (IPASS). J Clin Oncol 29:2866-2874

2. Ozretic L, Heukamp LC, Odenthal M et al. (2012) The role of molecular diagnostics in cancer diagnosis and treatment. Onkologie 35 (Suppl 1):812

3. Piccart-Gebhart MJ, Procter M, Leyland-Jones B et al. (2005) Trastuzumab after adjuvant chemotherapy in HER2-positive breast cancer. N Engl J Med 353:1659-1672

4. Buettner R, Wolf J, Thomas RK (2013) Lessons to learn from lung cancer genomics: The emerging concept of individualized diagnostics and treatment. J Clin Oncol [in Press] 